\title{
Otlatma Olgunluğu Döneminde Hindiba (Cichorium intybus L.) ile Bazı Baklagil ve Buğdaygil Yem Bitkileri Karışımlarının Ot Verimi ve Otun Bazı Özelliklerinin Belirlemesi
}

\author{
Mehmet CAN $^{1 *}$, Ilknur AYAN ${ }^{2}$
}

Revize / Revised: 22/10/2019

Kabul / Accepted: 22/10/2019

\section{ÖZ}

Bu çalışma, Ondokuz Mayıs Üniversitesi Ziraat Fakültesi Araştırma ve Uygulama alanında 2017 ve 2018 y1lında Tesadüf Blokları Deneme desenine göre yürütülmüştür. Materyal olarak hindiba ile yonca, ak üçül, çayır üçülü, gazal boynuzu, çok yıllık çim ve domuz ayrığı bitkilerinin yalın, ikili (hindiba+diğer yem bitkileri) ve üçlü (hindiba+baklagil+buğdaygil) karışımları kullanılmıştır. Çalışma hindibanın otlatma olgunluğu dönemine ulaştığında hasat edilmiştir. Biçimlerin ortalaması olarak hindibanın bitki boyu $19-56 \mathrm{~cm}$ arasında değişmiştir. İki yılda elde edilen toplam yaş ot verimleri $2564-20831 \mathrm{~kg} / \mathrm{da}$ arasında, toplam kuru ot verimi $772-4298 \mathrm{~kg} / \mathrm{da}$ arasında değişmiştir. Otlatma olgunluğu döneminde, kuru otun ortalama ham protein oranı sırasıyla, \% 11.85 26.80, NDF oranı \% 27.45-63.01, ADF oranı \% 15.45-34.23, NYD değeri 92-256 olarak belirlenmiştir. Çalışmanın sonuçları incelendiğinde, benzer ekolojilerde hindiba yapay mera tesisinde değerlendirilecekse çayır üçgülü+domuz ayrı̆̆ı 1 hindiba karışımı önerilebilir.

\footnotetext{
1*Sorumlu yazar iletișim: zir.mehmet@gmail.com (https://orcid.org/0000-0003-0230-6209)

Tarla Bitkileri Bölümü, Ondokuz Mayıs Üniversitesi, Kurupelit Kampüsü, Atakum, SAMSUN

2illetişim: ilknuray@omu.edu.tr (https://orcid.org/0000-0002-5097-9013)

Tarla Bitkileri Bölümü, Ondokuz Mayıs Üniversitesi, Kurupelit Kampüsü, Atakum, SAMSUN
} 


\title{
Determination of Some Forage Quality Parameters and Yield of Chicory Mixtures with Some Forage Grasses and Legumes at The Stage of Grazing Maturity
}

\begin{abstract}
A 2-year study was conducted in Ondokuz May University, the experimental area of Field Crops Department during the growing seasons of 2017- 2018 with randomized block design with three replications. Forage mixtures comprised combinations of alfalfa, white clover, red clover, birdsfood trefoil, perennial ryegrass and orchard grass along with chicory as pure stand, binary mixtures (chicory+other forage crops) and triple mixtures (chicory+legume+grass). Pasture plots were harvested at the grazing stage of chicory. The average of plant height of chicory was changed between $19-56 \mathrm{~cm}$. The total hay yield for the two years was ranged from 2564 to $20831 \mathrm{~kg} / \mathrm{da}$ while the total dry matter yield was changed between 772 and $4298 \mathrm{~kg} / \mathrm{da}$. The average crude protein, NDF, ADF and NYD content of pasture was observed 11.85-26.80\%, 15.45-636.01\% and 92-256, respectively. This study showed that red clover and orchard grass mixed with chicory can be suggested for the similar ecological conditions where the experiment conducted if chicory will be used as a part of mixture in the sown pasture systems.
\end{abstract}




\section{GIRIŞ}

Nüfusumuz, hayvan sayımız ve hayvansal ürünlere olan talep sürekli artarken, hayvanları beslemek için kullanmamız gereken kaliteli kaba yem üretimi yerinde saymaktadır. Zaten çok yetersiz olan kaliteli kaba yem üretimimiz, artan taleple birlikte iyice yetersiz hale gelmiştir [1]. Çayır ve meralardan beklenen faydanın elde edilememesinin yanı sıra tarla tarımı içerisinde yem bitkileri üretiminin de yetersiz olması kaba yem üretimimizin en önemli sorularındandır. Ülkemizde kırsal kesimde yaşanan göç sebebiyle küçük işletmelerin sayısı ve üretimdeki payı sürekli azalmaktadır. Buna karşılık, orta ve büyük ölçekli işletme sayımız ise artış göstermektedir [2]. Karlı bir üretim için orta ve büyük işletmeler kaba yem ihtiyaçlarını karşılamak amacıyla kiralama veya kendi arazilerinde hızla yapay mera kurma çalışmalarına başlamışlardır. Yapay meralar hayvancılık yapılan her işletme ya da yörede hayvanların kaba yem ihtiyaçlarını karşılayabilecek önemli yem üretim sistemidir [3]. Yapay mera tesislerinde yalın ekim yerine genelde karışık ekim önerilmektedir. Karışık ekim ile daha verimli, dengeli ve uzun süreli yem üretilmekte ayrıca tesisin başarı şansı artmaktadır [4]. Karışımlarda en az bir baklagil ve bir buğdaygil bulunmalıdır [5,6]. Türkiye'de yapay meralardan elde edilen kaba yemin üretim ve kalitesinin artırılması için yetiştiriciliği yapılan tür ve çeşitlerin artırılması gerekmektedir. $\mathrm{Bu}$ konuya önem veren birçok dünya ülkesinde yabani formlardan alternatif yem bitkisi tür ve çeşitleri geliştirilmiştir. Yeni Zelanda'da 1978 yılında gerçekleşen kuraklıkta verimi ve besleme değeri ile dikkat çeken hindiba (Cichorium intybus L.) bunun en güzel örneklerindendir. Hindiba bitkisinin ülkemiz doğal florasındaki dağılımı ve sıklığı, bitkinin ülkemiz ekolojisine uyumunu, potansiyel çeşitliliğini açıkça ortaya koymaktadır [7]. $\mathrm{Bu}$ amaçla, hindiba alternatif bir bitki olarak yem bitkileri tarımımıza ve hayvansal üretimimize önemli katkı sağlayabilecektir. Bu çalışma, otlatma olgunluğu döneminde hindiba (Cichorium intybus L.) ile bazı baklagil ve buğdaygil yem bitkileri karışımlarının ot verimi ve otun bazı özelliklerinin belirlemesi amacıyla yürütülmüştür.

\section{MATERYAL METOT}

Bu çalışma, Ondokuz Mayıs Üniversitesi Ziraat Fakültesi deneme alanında 2017-2018 yıllarında 2 yıl süreyle yürütülmüştür. Çalışmanın yürütüldüğü alanın toprak analizi sonucuna göre; toprağın tekstür bakımından killi (\% 45), hafif asit karakterli (6.34), tuzsuz (0.48 mmhos/cm), organik madde içeriği yüksek (\% 3.37) seviyede ve az kireçli (\% 2.18) olduğu, azot bakımından yeterli (\% 0.16), fosfor ve potasyum içeriğinin, ise çok yüksek (sırasıyla 65.40 ve 340 ppm) olduğu belirlenmiştir. Araştırmanın 2017 yılına ait ortalama en yüksek sıcaklık ve toplam yağış değerleri sırasıyla $15.2{ }^{\circ} \mathrm{C}$ ile $657.3 \mathrm{~mm}$ 'dir. 2018 yılında belirlenen ortalama sıcaklık ve toplam yağış değerleri sırasıyla $16.6^{\circ} \mathrm{C}$ ile $792.7 \mathrm{~mm}$ 'dir (Tablo 1).

Tablo 1. Samsun İline ait uzun yıllar ve deneme yıllarına ait bazı iklim verileri

\begin{tabular}{|c|c|c|c|c|c|c|c|c|c|}
\hline \multirow[b]{2}{*}{ Aylar } & \multicolumn{3}{|c|}{ Ortalama sıcaklık $\left({ }^{0} \mathrm{C}\right)$} & \multicolumn{3}{|c|}{ Toplam Yağıș (mm) } & \multicolumn{3}{|c|}{ Oransal Nem $(\%)$} \\
\hline & Uzun yıllar & 2017 & 2018 & Uzun yıllar & 2017 & 2018 & Uzun yıllar & 2017 & 2018 \\
\hline Ocak & 7.2 & 6.2 & 8.9 & 64.9 & 78.8 & 153.6 & 66.4 & 60.2 & 65.9 \\
\hline Şubat & 7.2 & 7.4 & 10.1 & 53.3 & 40.1 & 37.0 & 68.9 & 58.8 & 71.2 \\
\hline Mart & 8.2 & 9.4 & 11.5 & 61.6 & 65.1 & 118.9 & 74.5 & 71.3 & 72.7 \\
\hline Nisan & 11.3 & 10.2 & 12.7 & 58.7 & 78.3 & 6.8 & 78.0 & 73.7 & 69.5 \\
\hline Mayıs & 15.5 & 15.3 & 18.2 & 51.5 & 70.9 & 18.9 & 79.0 & 75.5 & 76.4 \\
\hline Haziran & 20.1 & 20.9 & 22.9 & 48.1 & 45.1 & 29.7 & 74.5 & 71.7 & 66.5 \\
\hline Temmuz & 23.1 & 24.2 & 25.3 & 34.3 & 0.4 & 39.7 & 72.3 & 64.8 & 64.6 \\
\hline Ağustos & 23.5 & 25.5 & 25.7 & 41.5 & 13.7 & 65.3 & 72.1 & 64.8 & 60.8 \\
\hline Eylül & 20.2 & 22.3 & 21.9 & 51.5 & 29.8 & 90.2 & 73.6 & 63.5 & 65.5 \\
\hline Ekim & 16.3 & 16.4 & 18.5 & 82.5 & 34.6 & 88.4 & 74.6 & 61.6 & 69.9 \\
\hline Kasım & 12.6 & 13.3 & 13.6 & 83.1 & 59.4 & 67.9 & 68.8 & 61.5 & 67.8 \\
\hline Aralık & 9.3 & 12.2 & 9.8 & 81.5 & 141.1 & 76.3 & 65.8 & 54.5 & 63.9 \\
\hline Ortalama & 14.5 & 15.2 & 16.6 & & & & 72.3 & 65.1 & 67.9 \\
\hline Toplam & & & & 712.5 & 657.3 & 792.7 & & & \\
\hline
\end{tabular}

Çalışmada Asteraceae familyasından hindibanın (Cichorium intybus L.) Grassland Puna II, baklagil yem bitkilerinden yoncanın (Medicago sativa L.) Dimitra, ak üçgülün (Trifolium repens L.) Liflex, çayır üçgülünün (Trifolium pratense L.) Suez, gazal boynuzunun (Lotus corniculatus L.) Lotus çeşiti, buğdaygil yem bitkilerinden çok yıllık çimin (Lolium perenne L.) Çim ve domuz ayrığının (Dactylis glomerata L.) Lidacta 
çeşidi kullanılmıştır. Çalışma tesadüf blokları deneme desenine göre 3 tekrarlı olarak kurulmuştur. Araştırmada kullanılan türler yalın, ikili (hindiba + baklagil/buğdaygil) ve üçlü (hindiba + baklagil + buğdaygil) karışımlar olarak ekilmiş ve toplam 21 işlemden (karışım) oluşmuştur. Sıra arası mesafe $20 \mathrm{~cm}$, parsel boyu $3.5 \mathrm{~m}$, yalın ekimlerde 4 sıra, ikili karışımlarda 6 sıra ve üçlü karışımlarda ise 9 sıra yer almıştır. Denemenin ekimi 28.02.2017 tarihinde elle yapılmıştır. Karışım parsellerinde türler farklı sıraya gelecek şekilde ekilmiştir. Ekimle birlikte $6 \mathrm{~kg} / \mathrm{da} \mathrm{P} 205$ ve $5 \mathrm{~kg} / \mathrm{da} \mathrm{N}$, sonbaharda tüm parsellere $2 \mathrm{~kg} / \mathrm{da} \mathrm{N}$ uygulanmıştır. İkinci yıl erken ilkbaharda baklagil bitkileri olan parsellere $2 \mathrm{~kg} / \mathrm{da}$, olmayan parsellere $4 \mathrm{~kg} / \mathrm{da} \mathrm{N}$ düşecek şekilde azotlu gübre uygulanmıştır. Deneme alanının toprak nemi dikkate alınarak 2017 yılında 7, 2018 yılında ise 2 sulama yapılmıştır. Deneme otlatmayı taklit edecek şekilde hindiba bitkileri $25-35 \mathrm{~cm}$ bitki boyuna ulaştıklarında, otlatma olgunluğu döneminde hasat edilmiştir. 2017 yılında, 13 Haziran (1. biçim), 10 Temmuz (2. biçim) ve 16 Ağustos (3. biçim); 2018 yılında ise 16 Nisan (1. biçim) ve 31 Mayıs (2. biçim) tarihlerinde hasat yapıllmıştır. Çalışmada biçim yapılmadan önce her bitki türünde 10 bitkide toprak seviyesinden yaprakların uç noktasına kadar olan kısım ölçülmüştür. Karışımı oluşturan parsellerin ortalama bitki boyu değerleri türlerin ve yılların ortalaması alınarak belirlemiştir. Yalın ve karışım parsellerinden biçilen bitkiler türlerine göre ayrılmış ve tartılarak dekara yaş ot verimi hesaplanmıştır. Kuru ot verimi ise hasat edilen parsellerden her bitki türünden 500 gr örnek alınarak $60{ }^{\circ} \mathrm{C}^{\prime}$ de sabit ağırlığa gelene kadar kurutulmuştur. Kurutulan örnekler tartılmış, elde edilen kuru ot oranları kullanılarak dekara kuru ot verimi hesaplanmıştır. Kuru ot örnekleri elek çapı 1 mm olan değirmende öğüülerek analize hazır duruma getirilmiştir. Örneklerin ham protein, ADF ve NDF oranları Foss NIRSystems Model 6500 Win ISI II v1.5 cihazında IC-0904FE kalibrasyon programı kullanılarak belirlenmiştir [8]. Nispi yem değeri ADF ve NDF değerleri kullanılarak hesaplanmıştır [9]. Çalışmadan elde edilen sonuçlar SPSS 17.0 istatistik paket programı kullanılarak her biçim için ayrı ayrı olacak şekilde 'Tesadüf Blokları Deneme Desenine' göre analiz edilmiştir. Ortalamalar arasındaki farklar Duncan Çoklu Karşılaştırma Testi kullanılarak değerlendirilmiştir.

\section{BULGULAR VE TARTIŞMA}

Otlatma olgunluğu döneminde ortalama bitki boyu değerleri birinci yıl 19-48 cm, ikinci yılda ise 24-56 cm arasında değişmiştir. Hindibanın bitki boyu değerleri 26-32 cm arasında belirlenmiştir (Şekil 1). Puna II çeşidi serin mevsimlerde aktif büyümesini sağlamakta ancak sıcaklığın $20{ }^{\circ} \mathrm{C}$ 'nin üzerine çıktığında gelişmesini yavaşlamaktadır [10]. Genel olarak, her iki yılda da en uzun bitki boyu değerleri yoncada belirlenmiştir. Yoncanın diğer yem bitkilerine göre çevreye adaptasyon kabiliyetinin ve biçimlerden sonra kendini yenileme hızının daha yüksek olduğunu belirtmektedirler [11]. Bitki boyu bakımından öne çıkan bir diğer bitki olan çayır üçgülü nemli ve serin iklimlere, ağır topraklara ve 1şık yoğunluğu düşük bölgelere iyi adapte olması nedeniyle Karadeniz bölgesinde bitkinin hızlı gelişmesine sebep olmaktadır [12,13]. Hindibanın en uygun otlatma yüksekliğinin 25-35 cm olduğunu bildirmişlerdir [14,15].

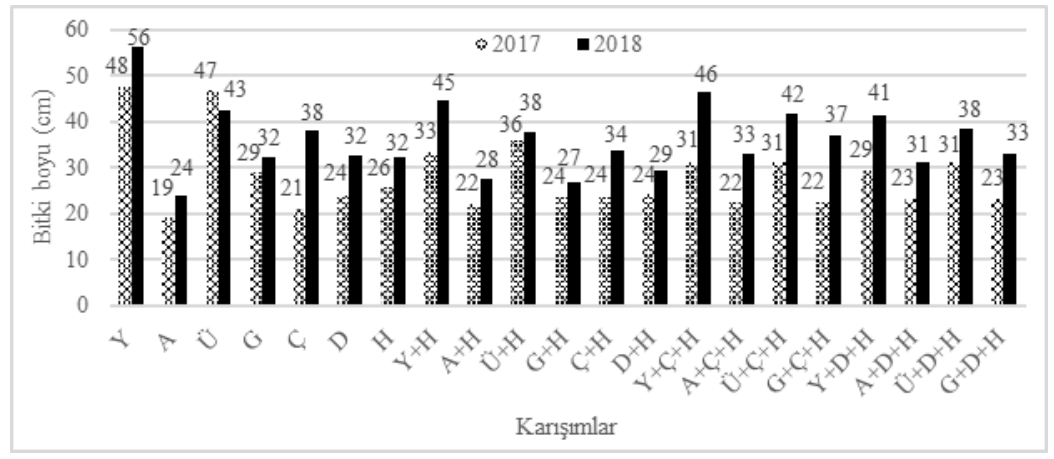

Şekil 1. 2017 ve 2018 y1lı işlemlere göre belirlenen ortalama bitki boyu değerleri $(\mathrm{cm})$

Hindiba ile diğer yem bitkilerinin yalın ve karışımlarının 2017 ve 2018 yılında yapılan biçimlerde belirlenen yaş ot verimi değerleri Tablo 2'de verilmiştir. Yaş ot verimi bakımından işlemler arasındaki farklılığın istatistiksel olarak çok önemli olduğu belirlenmiştir. 2017 yılının 1. biçiminde en yüksek yaş ot verimi Ü+D $+\mathrm{H}$ 
karışımında (4366 kg/da), en düşük yaş ot verimi ise $432 \mathrm{~kg} / \mathrm{da}$ ile yalın gazal boynuzundan elde edilmiştir. İkinci biçimde en yüksek yaş ot verimi $1854 \mathrm{~kg} / \mathrm{da}$ ile Ü+Ç+H karışımında, en düşük ise yalın domuz ayrığında belirlenmiştir. Üçüncü biçimde belirlenen yaş ot verimleri 343-4978 kg/da arasında değişmiştir. 2018 yılının birinci biçimde en yüksek yaş ot verimi $\ddot{U}+C ̧+H(6789 \mathrm{~kg} / \mathrm{da})$ karışımında, en düşük yaş ot verimi ise yalın domuz ayrığından $(513 \mathrm{~kg} / \mathrm{da})$ elde edilmiştir. Denemenin ikinci yılı 2. biçiminde en yüksek yaş ot verimi $\mathrm{Y}+\mathrm{C}+\mathrm{H}(3663 \mathrm{~kg} / \mathrm{da})$ karışımında elde edilmiştir. İki yılda elde edilen toplam yaş ot verimi $2564-20831 \mathrm{~kg} / \mathrm{da}$ arasında değişmiştir. Çalışmanın yürütüldüğü alanın toprak derinliğinin az olmasından dolayı [16], hindiba iyi bir kök gelişimi sağlayamamış ve sıcaklık stresinin olumsuz etkisi olmuştur. Hindibanın derin, verimli, killi tınlı topraklarda daha iyi yetişen, yaz sıcaklarını orta derecede tolere eden bir serin mevsim bitkisi olduğunu belirtmektedirler [17]. Kuru ot verimi bakımından işlemler arasındaki farklılığın istatistiksel olarak çok önemli olduğu belirlenmiştir (Tablo 2). 2017 yılının 1. biçiminde en yüksek kuru ot verimi Ü+D+H (646 kg/da) karışımında, en düşük ise $72 \mathrm{~kg} /$ da ile yalın gazal boynuzundan elde edilmiştir. Yapılan 2. biçimde belirlenen en yüksek kuru ot verimi $\ddot{U}+\mathrm{D}+\mathrm{H}$ karışımında, en düşük kuru ot verimi ise yalın domuz ayrığından elde edilmiştir. Üçüncü biçimde belirlenen kuru ot verimleri $95-1199 \mathrm{~kg} / \mathrm{da}$ arasında değişmiştir. Çalışmanın 1. yılında en yüksek kuru ot verimleri çayır üçgülünün yer aldığı karışımlarda belirlenmiştir. Karadeniz Bölgesi toprak ve iklim koşulları üçgül yetiştiriciliği için oldukça uygundur [18]. Çalışmamızda üçgüller ile hindiba gelişiminin birbiri ile uyumlu olduğu görülmektedir [15]. 2018 yılının birinci biçimde en yüksek kuru ot verimi $\ddot{U}+C ̧+H$ $(1130 \mathrm{~kg} / \mathrm{da})$ karışımında, en düşük ise yalın domuz ayrığında $(121 \mathrm{~kg} / \mathrm{da})$ belirlenmiştir. Çalışmanın ikinci yılı 2. biçiminde en yüksek kuru ot verimi üçlü karışımlarda belirlenmiş $(610-858 \mathrm{~kg} / \mathrm{da})$ ve Ü+D+H karışımı dışındaki bütün üçlü karışımlar aynı istatistiki grup içerisinde yer almıştır. Bu biçimde en düşük kuru ot verimi yalın olarak yetiştirilen çok yıllık çim parselinde belirlenmiş ve yalın yonca hariç, diğer yalın yetiştirilen bitkilerle aynı istatistiki grupta yer almıştır. İki yılda elde edilen toplam kuru ot verim değerleri 723-4298 kg/da arasında değişmiştir.

Tablo 2. Otlatma olgunluğu döneminde hindiba ile bazı yem bitkileri karışımlarından elde edilen yaş ve kuru ot verimleri (kg/da)

\begin{tabular}{|c|c|c|c|c|c|c|c|c|c|c|c|c|}
\hline \multirow{3}{*}{ Karıșımlar } & \multicolumn{6}{|c|}{ Yaş Ot Verimi (kg/da) } & \multicolumn{6}{|c|}{ Kuru Ot Verimi (kg/da) } \\
\hline & \multicolumn{3}{|c|}{2017} & \multicolumn{2}{|c|}{2018} & \multirow{2}{*}{ Toplam } & \multicolumn{3}{|c|}{2017} & \multicolumn{2}{|c|}{2018} & \multirow{2}{*}{ Toplam } \\
\hline & 1. Biç & 2. Biç & 3. Biç & 1. Biç & 2. Biç & & 1. Biç & 2. Biç & 3. Biç & 1. Biç & 2. Biç & \\
\hline $\mathbf{Y}$ & $964 \mathrm{eg}$ & $540 \mathrm{dg}$ & $886 \mathrm{eg}$ & $1880 \mathrm{fh}$ & $1543 \mathrm{cf}$ & 5813hj & $220 \mathrm{gk}$ & $184 \mathrm{de}$ & $272 \mathrm{fh}$ & $405 \mathrm{eh}$ & $399 \mathrm{dh}$ & $1480 \mathrm{fj}$ \\
\hline $\mathbf{A}$ & $1750 \mathrm{cg}$ & $505 \mathrm{eg}$ & $1380 \mathrm{dg}$ & $2752 \mathrm{dh}$ & $681 \mathrm{ef}$ & $7068 \mathrm{gj}$ & $237 \mathrm{gk}$ & $165 \mathrm{de}$ & $287 \mathrm{eh}$ & 414eh & $222 \mathrm{~g} 1$ & $1326 \mathrm{hk}$ \\
\hline$\ddot{\mathbf{U}}$ & $3082 \mathrm{ac}$ & $972 \mathrm{ce}$ & 2364 ce & $3276 \mathrm{cg}$ & $651 \mathrm{ef}$ & $10344 \mathrm{dh}$ & $467 b$ & $302 \mathrm{be}$ & $670 \mathrm{bd}$ & $536 \mathrm{cg}$ & $177 \mathrm{~h} 1$ & $2151 \mathrm{dg}$ \\
\hline $\mathbf{G}$ & $432 \mathrm{~g}$ & $559 \mathrm{dg}$ & $2087 \mathrm{cf}$ & 2057eh & $1576 \mathrm{ce}$ & $6710 \mathrm{gj}$ & $72 \mathrm{k}$ & $171 \mathrm{de}$ & $481 \mathrm{cg}$ & $352 \mathrm{fh}$ & $335 \mathrm{fi}$ & $1412 \mathrm{gk}$ \\
\hline Ç & $567 \mathrm{fg}$ & $396 \mathrm{fg}$ & $500 \mathrm{fg}$ & $920 \mathrm{gh}$ & $365 f$ & $27491 j$ & $114 \mathrm{k}$ & $135 \mathrm{de}$ & $167 \mathrm{gh}$ & $226 \mathrm{gh}$ & 1301 & 772jk \\
\hline D & $517 \mathrm{fg}$ & $185 \mathrm{~g}$ & $343 \mathrm{~g}$ & $513 \mathrm{~h}$ & $1006 \mathrm{df}$ & $2564 j$ & $105 \mathrm{jk}$ & $64 \mathrm{e}$ & $95 \mathrm{~h}$ & $121 \mathrm{~h}$ & $338 \mathrm{fi}$ & $723 \mathrm{k}$ \\
\hline $\mathbf{H}$ & 1937be & 979ce & $1138 \mathrm{dg}$ & $1869 f h$ & $1407 \mathrm{cf}$ & $7330 \mathrm{~g}_{1}$ & $265 f j$ & $182 \mathrm{de}$ & $195 \mathrm{gh}$ & $244 \mathrm{gh}$ & $229 \mathrm{~g}_{1}$ & $11161 \mathrm{k}$ \\
\hline $\mathbf{Y}+\mathbf{H}$ & $1792 \mathrm{bf}$ & $841 \mathrm{cf}$ & $1761 \mathrm{cg}$ & $2703 \mathrm{dh}$ & $2153 \mathrm{bd}$ & 9250eh & $293 \mathrm{~d}_{1}$ & $217 \mathrm{de}$ & $408 \mathrm{ch}$ & $490 \mathrm{cg}$ & $437 \mathrm{dg}$ & $1844 \mathrm{e} 1$ \\
\hline $\mathbf{A}+\mathbf{H}$ & $2463 b d$ & 1094bd & $2488 \mathrm{ce}$ & $4412 \mathrm{ae}$ & $1942 \mathrm{~cd}$ & $12399 d f$ & $357 \mathrm{dh}$ & 270de & $453 \mathrm{cg}$ & $619 b f$ & $444 d g$ & $2143 \mathrm{dg}$ \\
\hline$\ddot{\mathbf{U}}+\mathbf{H}$ & $4269 a$ & $1816 a$ & $4117 \mathrm{ab}$ & $5639 \mathrm{ac}$ & $2164 \mathrm{bd}$ & $18004 \mathrm{ac}$ & $595 \mathrm{ab}$ & $526 \mathrm{~b}$ & $933 \mathrm{ab}$ & $854 \mathrm{ac}$ & $467 \mathrm{cg}$ & $3374 b$ \\
\hline $\mathbf{G}+\mathbf{H}$ & $1808 \mathrm{bf}$ & $1089 \mathrm{bd}$ & $3151 b c$ & $3079 \mathrm{dg}$ & $2053 \mathrm{bd}$ & 11180de & $240 \mathrm{gk}$ & 260ce & $668 \mathrm{bd}$ & 421eh & $426 \mathrm{dh}$ & 2014dh \\
\hline $\mathbf{C}+\mathbf{H}$ & $2356 \mathrm{bd}$ & $827 \mathrm{cf}$ & $1388 \mathrm{dg}$ & $2497 \mathrm{dh}$ & $1462 \mathrm{cf}$ & 8529fh & $395 \mathrm{cg}$ & 199de & 298eh & 437eh & $365 \mathrm{e} 1$ & $1695 \mathrm{fi}$ \\
\hline D+H & $2467 \mathrm{bd}$ & 1023be & $1521 \mathrm{dg}$ & 2257eh & 1672ce & 8941 eh & $335 \mathrm{dh}$ & 209de & $346 \mathrm{dh}$ & 389eh & $387 \mathrm{dh}$ & $1666 \mathrm{fi}$ \\
\hline $\mathbf{Y}+\mathbf{C}+\mathbf{H}$ & $2201 \mathrm{be}$ & $1389 \mathrm{ac}$ & $2554 \mathrm{~cd}$ & 4969ad & $3663 a$ & 14776bd & 344dh & $349 \mathrm{bd}$ & $608 \mathrm{bf}$ & $927 \mathrm{ab}$ & $858 \mathrm{a}$ & $3086 b c$ \\
\hline $\mathbf{A}+\mathbf{C}+\mathbf{H}$ & $3164 \mathrm{ab}$ & $1314 \mathrm{ac}$ & $4567 \mathrm{ab}$ & $6725 a$ & $2563 \mathrm{ac}$ & $18333 \mathrm{ab}$ & $436 \mathrm{bf}$ & $344 \mathrm{bd}$ & $748 b c$ & $1073 a$ & $639 \mathrm{ad}$ & $3239 b c$ \\
\hline$\ddot{\mathbf{U}}+\mathbf{C}+\mathbf{H}$ & $3878 \mathrm{a}$ & $1854 \mathrm{a}$ & 4835a & $6789 a$ & $3475 a$ & 20831a & $567 \mathrm{ac}$ & $505 b c$ & $1199 a$ & $1130 \mathrm{a}$ & $829 a b$ & $4229 a$ \\
\hline $\mathbf{G}+\mathbf{C}+\mathbf{H}$ & $1345 \mathrm{dg}$ & $900 \mathrm{cf}$ & $2000 \mathrm{cf}$ & 3906bf & 3198ab & 11349 de & 194hk & $218 \mathrm{de}$ & $413 \mathrm{ch}$ & 696be & $703 \mathrm{ac}$ & $2223 \mathrm{df}$ \\
\hline $\mathbf{Y}+\mathbf{D}+\mathbf{H}$ & $2385 b d$ & $1109 \mathrm{bd}$ & $1919 \mathrm{cg}$ & $3529 \mathrm{cf}$ & $3180 \mathrm{ab}$ & $12122 \mathrm{df}$ & $357 \mathrm{dh}$ & 283be & $493 \mathrm{cg}$ & $652 \mathrm{bf}$ & $750 \mathrm{ab}$ & 2536ce \\
\hline $\mathrm{A}+\mathrm{D}+\mathbf{H}$ & $2222 \mathrm{be}$ & $1174 b c$ & $3255 \mathrm{bc}$ & $4841 \mathrm{ad}$ & $2241 b c$ & 13733 ce & $313 \mathrm{dh}$ & $320 \mathrm{be}$ & $617 \mathrm{be}$ & $814 \mathrm{ad}$ & $610 \mathrm{ae}$ & $2673 b d$ \\
\hline$\ddot{\mathbf{U}}+\mathbf{D}+\mathbf{H}$ & $4366 a$ & 1730a & $4978 \mathrm{a}$ & 5998ab & $2557 \mathrm{ac}$ & $19629 a$ & $646 a$ & $827 a$ & $1149 a$ & $1092 a$ & $585 b f$ & $4298 \mathrm{a}$ \\
\hline $\mathbf{G}+\mathbf{D}+\mathbf{H}$ & $1638 \mathrm{dg}$ & $1596 \mathrm{ab}$ & $2528 \mathrm{ce}$ & $3915 b f$ & $3474 a$ & $13152 \mathrm{df}$ & $230 \mathrm{gk}$ & $335 \mathrm{bd}$ & $578 \mathrm{cf}$ & $664 \mathrm{bf}$ & $767 \mathrm{ab}$ & $2574 \mathrm{ce}$ \\
\hline
\end{tabular}

*Aynı sütunda, aynı harfle gösterilen ortalamalar arasında 0.01 seviyesinde farklılık yoktur. Y:Yonca, A:Ak üçgül, Ü:Çayır Üçgülü, G:Gazal boynuzu, Ç:Çok yıllık çim, D:Domuz ayrı̆̆ı ve H:Hindiba. 
Yalın ekimler içerisinde 2 yıllık toplam kuru ot verimi bakımından en düşük değerler domuz ayrığı ve çimden elde edilmiştir. Bu durum çok büyük ihtimalle bitkilere uygulanan azot miktarının az olmasından kaynaklanmıştır. Nitekim yalın ekimlerde buğdaygil yem bitkileri için su durumuna bağlı olarak 5-10 kg N/da tavsiye edilmektedir. Hindibanın verimi baklagillerden az ancak buğdaygillerden yüksek olmuştur. Hindiba derin köklü olması nedeniyle toprak derinlerindeki besinlerden buğdaygillere göre daha rahat faydalanabilmektedir. Baklagiller ise özellikle biyolojik azot fiksasyonu sayesinde diğer 2 türe göre daha fazla verim vermişlerdir. Karışımlar yalın ekimlerden daha verimli olmakla birlikte, karışımda kullanılan türlere ve karışım oranına bağlı olarak elde edilen toplam verim değişim göstermiştir. Karışık ekimlerle yapılan çalışmalarda genellikle karışımların yalın ekimlerden üstün olduğu, ancak karışımdan elde edilen verimin karışımda kullanılan türe, ekim oranına ve hasat zamanına bağlı olarak değiştiği [19,20,21] bildirilmiştir.

Tablo 3. Otlatma olgunluğu döneminde hindiba ile bazı yem bitkileri karışımlarından elde edilen ham protein ve ADF oranları

\begin{tabular}{|c|c|c|c|c|c|c|c|c|c|c|}
\hline \multirow{3}{*}{ Karışımlar } & \multicolumn{5}{|c|}{ Ham Protein (\%) } & \multicolumn{5}{|c|}{ ADF (\%) } \\
\hline & \multicolumn{3}{|c|}{2017} & \multicolumn{2}{|c|}{2018} & \multicolumn{3}{|c|}{2017} & \multicolumn{2}{|c|}{2018} \\
\hline & 1. Biç & 2. Biç & 3. Biç & 1. Biç & 2. Biç & 1. Biç & 2. Biç & 3. Biç & 1. Biç & 2. Biç \\
\hline $\mathbf{Y}$ & $24.50 \mathrm{ac}$ & $21.82 \mathrm{ad}$ & $23.59 \mathrm{a}$ & $22.03 \mathrm{bf}$ & $23.06 \mathrm{a}$ & $27.68 \mathrm{bd}$ & $26.53 \mathrm{cg}$ & $25.14 \mathrm{dg}$ & $25.65 \mathrm{ab}$ & $27.21 \mathrm{ef}$ \\
\hline $\mathbf{A}$ & $26.18 \mathrm{a}$ & $21.64 \mathrm{bd}$ & $24.23 \mathrm{a}$ & $26.80 \mathrm{a}$ & 19.58be & 24.69ce & $23.10 \mathrm{~h} 1$ & $20.50 \mathrm{~h}$ & $17.23 \mathrm{fg}$ & $27.96 \mathrm{cf}$ \\
\hline$\ddot{\mathbf{U}}$ & $24.61 \mathrm{ac}$ & $21.33 \mathrm{bd}$ & $22.12 \mathrm{a}$ & $22.18 b f$ & $21.30 \mathrm{ac}$ & $30.30 \mathrm{ab}$ & $30.81 b$ & $30.32 b$ & $22.69 \mathrm{bd}$ & $29.78 \mathrm{cf}$ \\
\hline $\mathbf{G}$ & $25.35 \mathrm{ab}$ & $21.20 \mathrm{de}$ & $22.25 \mathrm{a}$ & $24.47 \mathrm{ab}$ & $23.55 \mathrm{a}$ & $21.59 \mathrm{e}$ & 22.541 & $24.56 \mathrm{eh}$ & $15.45 \mathrm{~g}$ & $22.74 \mathrm{~g}$ \\
\hline Ç & $17.68 \mathrm{f}$ & $17.31 \mathrm{f}$ & $17.45 \mathrm{c}$ & $14.32 \mathrm{~h}$ & $11.85 \mathrm{~h}$ & $29.39 \mathrm{ac}$ & $29.37 b c$ & $33.84 \mathrm{a}$ & $26.39 \mathrm{a}$ & $33.77 \mathrm{ab}$ \\
\hline D & $16.66 f$ & $16.91 \mathrm{f}$ & $18.55 b c$ & $18.33 \mathrm{~g}$ & $13.42 \mathrm{gh}$ & $33.44 \mathrm{a}$ & $34.23 \mathrm{a}$ & $34.18 \mathrm{a}$ & $23.79 \mathrm{ac}$ & $34.22 \mathrm{a}$ \\
\hline $\mathbf{H}$ & $23.36 \mathrm{ad}$ & $23.85 \mathrm{a}$ & $23.56 \mathrm{a}$ & 22.63be & $18.75 \mathrm{de}$ & $27.56 \mathrm{bd}$ & $24.28 \mathrm{fi}$ & $21.52 \mathrm{gh}$ & $22.46 \mathrm{bd}$ & $27.37 \mathrm{ef}$ \\
\hline $\mathbf{Y}+\mathbf{H}$ & 23.30ad & $23.41 \mathrm{ab}$ & $24.94 \mathrm{a}$ & $21.98 \mathrm{bf}$ & $21.81 \mathrm{ab}$ & $25.55 \mathrm{be}$ & $25.27 \mathrm{e} 1$ & $23.50 \mathrm{eh}$ & $21.63 \mathrm{ce}$ & $26.50 \mathrm{f}$ \\
\hline $\mathbf{A}+\mathbf{H}$ & $24.34 \mathrm{ac}$ & $22.18 \mathrm{ac}$ & $22.61 \mathrm{a}$ & $23.51 \mathrm{bd}$ & $20.05 \mathrm{bd}$ & 23.04de & $23.90 \mathrm{~g}_{1}$ & $22.53 \mathrm{fh}$ & $20.27 \mathrm{cf}$ & $26.44 \mathrm{f}$ \\
\hline$\ddot{\mathbf{U}}+\mathbf{H}$ & $24.17 \mathrm{ac}$ & $22.29 \mathrm{ac}$ & $23.08 \mathrm{a}$ & 22.71be & $21.58 \mathrm{ab}$ & $28.31 \mathrm{bd}$ & $27.76 \mathrm{cf}$ & $28.72 b d$ & $22.59 \mathrm{bd}$ & $27.69 \mathrm{df}$ \\
\hline $\mathbf{G}+\mathbf{H}$ & $24.31 \mathrm{ac}$ & $22.58 \mathrm{ac}$ & $22.66 a$ & $23.76 b c$ & $21.80 \mathrm{ab}$ & 23.50de & $23.64 g_{1}$ & $21.37 \mathrm{gh}$ & $18.32 \mathrm{eg}$ & $22.34 \mathrm{~g}$ \\
\hline $\mathbf{C}+\mathbf{H}$ & $19.06 \mathrm{ef}$ & $20.63 \mathrm{de}$ & $21.89 \mathrm{a}$ & $18.54 \mathrm{~g}$ & $14.35 \mathrm{~g}$ & $27.38 \mathrm{bd}$ & $26.61 \mathrm{cg}$ & $24.03 \mathrm{eh}$ & $22.47 \mathrm{bd}$ & $31.74 \mathrm{ad}$ \\
\hline D+H & $20.65 \mathrm{de}$ & $20.52 \mathrm{de}$ & $22.40 \mathrm{a}$ & $18.44 \mathrm{~g}$ & $15.77 \mathrm{fg}$ & $27.17 \mathrm{bd}$ & $25.91 \mathrm{dh}$ & $24.16 \mathrm{eh}$ & $23.10 \mathrm{ad}$ & $31.90 \mathrm{ac}$ \\
\hline $\mathbf{Y}+\mathbf{C}+\mathbf{H}$ & $22.98 \mathrm{bd}$ & $21.46 b d$ & $23.20 \mathrm{a}$ & $19.50 \mathrm{fg}$ & $18.40 \mathrm{de}$ & 25.36be & $27.07 \mathrm{ce}$ & $25.28 \mathrm{dg}$ & $23.73 \mathrm{ac}$ & $29.56 \mathrm{cf}$ \\
\hline $\mathbf{A}+\mathbf{C}+\mathbf{H}$ & $22.16 \mathrm{~cd}$ & $20.67 \mathrm{de}$ & $21.40 \mathrm{ab}$ & $23.39 \mathrm{be}$ & $18.11 \mathrm{df}$ & $25.32 \mathrm{be}$ & $25.34 \mathrm{e} 1$ & 26.68be & $19.62 \mathrm{df}$ & $28.86 \mathrm{cf}$ \\
\hline$\ddot{\mathbf{U}}+\mathbf{C}+\mathbf{H}$ & $22.73 b d$ & $20.68 \mathrm{de}$ & $22.32 \mathrm{a}$ & $21.65 \mathrm{cf}$ & $18.08 \mathrm{df}$ & $29.13 \mathrm{ac}$ & $28.72 b d$ & $29.48 b c$ & $22.38 \mathrm{bd}$ & $30.33 \mathrm{af}$ \\
\hline $\mathbf{G}+\mathbf{C}+\mathbf{H}$ & $21.66 \mathrm{ce}$ & $21.24 \mathrm{bd}$ & $22.40 \mathrm{a}$ & $20.64 \mathrm{eg}$ & $16.99 \mathrm{ef}$ & $26.17 \mathrm{be}$ & $24.63 \mathrm{fl}$ & $22.56 \mathrm{fh}$ & $19.68 \mathrm{df}$ & $29.20 \mathrm{cf}$ \\
\hline $\mathrm{Y}+\mathrm{D}+\mathrm{H}$ & $21.89 \mathrm{~cd}$ & $20.61 \mathrm{de}$ & $22.55 a$ & $20.89 \mathrm{dg}$ & $18.33 \mathrm{df}$ & $26.80 \mathrm{be}$ & $27.90 \mathrm{bf}$ & $26.40 \mathrm{cf}$ & $21.38 \mathrm{ce}$ & $31.24 \mathrm{ae}$ \\
\hline$A+D+H$ & $22.06 \mathrm{~cd}$ & $19.94 \mathrm{e}$ & $23.62 \mathrm{a}$ & $23.66 \mathrm{bd}$ & $17.91 \mathrm{df}$ & 26.04be & $25.15 \mathrm{e} 1$ & $23.80 \mathrm{eh}$ & $20.18 \mathrm{cf}$ & $29.87 \mathrm{bf}$ \\
\hline$\ddot{\mathbf{U}}+\mathbf{D}+\mathbf{H}$ & $22.52 \mathrm{bd}$ & $22.03 \mathrm{ad}$ & $24.45 \mathrm{a}$ & $22.10 \mathrm{bf}$ & $18.95 \mathrm{ce}$ & $29.68 \mathrm{ac}$ & $28.20 \mathrm{bf}$ & $29.47 b c$ & $22.30 \mathrm{bd}$ & 30.34af \\
\hline $\mathbf{G}+\mathbf{D}+\mathbf{H}$ & $21.96 \mathrm{~cd}$ & $20.92 \mathrm{de}$ & $22.46 \mathrm{a}$ & $21.55 \mathrm{cf}$ & $17.21 \mathrm{ef}$ & 24.41ce & $25.13 \mathrm{e} 1$ & $22.17 \mathrm{gh}$ & $20.49 \mathrm{cf}$ & $30.41 \mathrm{af}$ \\
\hline
\end{tabular}

*Aynı sütunda, aynı harfle gösterilen ortalamalar arasında 0.01 seviyesinde farklılık yoktur. Y:Yonca, A:Ak üçgül, Ü:Çayır Üçgülü, G:Gazal boynuzu, Ç:Çok yıllık çim, D:Domuz ayrı̆̆ı ve H:Hindiba.

Yaş ve kuru ot verimleri incelendiğinde, yalın hindiba ot verimi ile diğer yem bitkilerinin yalın ot verimleri toplandığında, hindiba ile karışık ekilen parsellerden daha düşük olduğu belirlenmiştir. Bu durum hindibanın toprağın daha alt katmanlarından su ve besin maddelerini alması ve toprak seviyesine taşıması ile diğer bitkilerin bundan yararlanması olarak açıklanabilir [22]. Hindibanın ilk biçiminde elde edilen kuru ot verimi diğer biçimlere göre daha yüksektir. Bu durum hindibanın uzun gün bitkisi olmasından kaynaklanmakta olup, bu beklenen bir durumdur [14]. Otlatma olgunluğu döneminde hindibadan elde edilen kuru ot verimleri bazı araştırıcıların bildirdiği verimlere benzer ya da daha fazla olmuştur [23,24,25,26]. Bu durum toprak, çevre, kullanılan çeşit özelliği ve uygulanan bakım işlemleri ile açıklanabilir. Kuru otun ortalama ham protein oranı bakımından bütün biçimlerde işlemler arasındaki farklılığın istatistiksel olarak çok önemli olduğu belirlenmiştir (Tablo 3). Ortalama ham protein değerleri birinci biçimde \%16.66-26.18 arasında değişmiştir. İkinci biçim ortalama ham protein oranı en yüksek yalın hindiba parselinde (\%23.85) belirlenmiştir. Araştırmanın 3. biçiminde en düşük ham protein oranı yalın çok yıllık çim \%17.45, en yüksek ise $\% 24.94$ ile $\mathrm{Y}+\mathrm{H}$ karışımında 
belirlenmiştir. 2018 yılı birinci biçimde, ortalama ham protein oranı en yüksek \%26.80 ile yalın ak üçgülde, en düşük ise yalın çok yıllık çim parselinde (\%14.32) belirlenmiştir. İkinci biçimde ortalama ham protein oranı en yüksek yalın gazal boynuzu, ikili karışımlarda $\mathrm{G}+\mathrm{H}$, üçlü karışımlarda ise $\mathrm{U}+\mathrm{D}+\mathrm{H}$ belirlenmiştir. Ham protein oranı bakımından bitki türleri, bitki organları arasında farklılıklar bulunmaktadır. Bilindiği üzere baklagiller buğdaygillere göre daha fazla ham protein oranına sahipken, yapraklar da gövdeye göre daha fazla ham protein içerirler. Ayrıca iklim şartları da bitki gelişimini etkileyerek bitkilerin kimyasal yapısını değiştirir [27]. Bu nedenlerle aynı biçimde işlemler arasında ham protein oranının farklı olası ve işlemlerden elde edilen ham protein oranının biçimlere göre değişmesi beklenen bir durumdur. Çalışmada belirlenen hindibanın ham protein oranları, bazı araştırmacılardan daha yüksek [28] bulunmuştur. Bu durum, toprak ve iklim koşulları, karışımlarda bulunan bitki tür/çeşitleri ve oranları ile hasat zamanı farklılıklarından kaynaklanmış olabilir. Ortalama ADF oranı bakımından işlemler arasındaki farklılığın istatistiksel olarak çok önemli olduğu belirlenmiştir (Tablo 3). 2017 yılının 1. biçiminde ortalama ADF oranın değerleri \%21.59-33.44 arasında değişmiştir. Aynı yılın ikinci biçiminden en yüksek ortalama ADF oranı yalın domuz ayrığı işleminde (\%34.23) belirlenirken, en düşük ise yalın gazal boynuzu (\%22.54) parselinden elde edilmiştir. Çalışmanın üçüncü biçimden ortalama ADF oranı \%20.50-33.84 arasında değişmiştir. Çalışmanın ikinci yılı birinci biçimde en yüksek ortalama ADF oranı yalın çok yıllık çim (\%26.39), en düşük ise yalın gazal boynuzundan (\%15.45) elde edilmiştir. İkinci biçimde en yüksek ortalama ADF oranı \%34.22 ile yalın domuz ayrı̆̆ı parselinden, en düşük ise yalın gazal boynuzu (\%22.74) parselinde belirlenmiştir.

Tablo 4. Otlatma olgunluğu döneminde hindiba ile bazı yem bitkileri karışımlarından elde edilen NDF oranı (\%) ve nispi yem değeri

\begin{tabular}{|c|c|c|c|c|c|c|c|c|c|c|}
\hline \multirow{3}{*}{ Karışımlar } & \multicolumn{5}{|c|}{ NDF (\%) } & \multicolumn{5}{|c|}{ NYD } \\
\hline & \multicolumn{3}{|c|}{2017} & \multicolumn{2}{|c|}{2018} & \multicolumn{3}{|c|}{2017} & \multicolumn{2}{|c|}{2018} \\
\hline & 1. Biç & 2. Biç & 3. Biç & 1. Biç & 2. Biç & 1. Biç & 2. Biç & 3. Biç & 1. Biç & 2. Biç \\
\hline $\mathbf{Y}$ & $34.67 \mathrm{df}$ & $34.71 \mathrm{fi}$ & $34.13 \mathrm{dg}$ & $36.34 \mathrm{ce}$ & $38.51 \mathrm{jk}$ & $185 \mathrm{ad}$ & $184 \mathrm{ae}$ & 190ad & $176 \mathrm{dg}$ & $166 \mathrm{ab}$ \\
\hline $\mathbf{A}$ & $34.02 \mathrm{df}$ & 31.731 & $30.84 \mathrm{~g}$ & $28.68 \mathrm{gh}$ & $39.481 \mathrm{k}$ & $197 \mathrm{ab}$ & $209 a$ & $220 a$ & $256 a$ & $159 \mathrm{bc}$ \\
\hline$\ddot{\mathbf{U}}$ & $43.15 b c$ & $41.13 c$ & $42.56 b$ & $37.23 \mathrm{c}$ & $45.89 \mathrm{eh}$ & $141 \mathrm{df}$ & $147 h_{1}$ & $144 \mathrm{f}$ & $179 \mathrm{cf}$ & $133 \mathrm{dg}$ \\
\hline $\mathbf{G}$ & 33.80ef & $33.17 \mathrm{~h} 1$ & $36.54 \mathrm{cf}$ & $27.45 \mathrm{~h}$ & $36.51 \mathrm{k}$ & $207 a$ & $200 \mathrm{ab}$ & 178be & $262 a$ & $182 \mathrm{a}$ \\
\hline Ç & $47.76 b$ & $46.93 b$ & $57.43 \mathrm{a}$ & $45.63 \mathrm{a}$ & $60.73 a$ & 130ef & 1311 & $101 \mathrm{~g}$ & $139 \mathrm{~h}$ & 96h1 \\
\hline D & $55.88 \mathrm{a}$ & $59.18 \mathrm{a}$ & $61.72 \mathrm{a}$ & 46.41a & 63.01a & $105 f$ & $98 \mathrm{k}$ & $94 \mathrm{~g}$ & $141 \mathrm{gh}$ & 921 \\
\hline $\mathbf{H}$ & $37.94 \mathrm{cf}$ & $35.09 \mathrm{e} 1$ & $33.80 \mathrm{eg}$ & $36.92 \mathrm{~cd}$ & $41.76 \mathrm{~h} 1$ & $176 \mathrm{ad}$ & $186 a \mathrm{ae}$ & $201 \mathrm{ab}$ & $182 \mathrm{cf}$ & $151 b d$ \\
\hline $\mathbf{Y}+\mathbf{H}$ & $35.08 \mathrm{df}$ & $33.88 \mathrm{~g}_{1}$ & $34.04 \mathrm{dg}$ & $32.84 \mathrm{df}$ & $38.80 \mathrm{jk}$ & $188 \mathrm{ac}$ & $191 \mathrm{ad}$ & $193 \mathrm{ad}$ & 204be & $165 \mathrm{ab}$ \\
\hline $\mathbf{A}+\mathbf{H}$ & $32.75 \mathrm{f}$ & $32.84 \mathrm{~h} 1$ & $33.53 \mathrm{fg}$ & $32.30 \mathrm{eg}$ & $40.161 \mathrm{k}$ & $207 a$ & $200 \mathrm{ac}$ & $198 \mathrm{ac}$ & $213 b c$ & $158 \mathrm{bc}$ \\
\hline$\ddot{\mathbf{U}}+\mathbf{H}$ & $40.65 \mathrm{~cd}$ & $38.56 \mathrm{cf}$ & $41.63 b c$ & $36.60 \mathrm{~cd}$ & $43.49 \mathrm{~g}_{1}$ & 153be & $162 \mathrm{eh}$ & $150 \mathrm{ef}$ & $182 \mathrm{cf}$ & $145 \mathrm{be}$ \\
\hline $\mathbf{G}+\mathbf{H}$ & $34.07 \mathrm{df}$ & $33.04 \mathrm{~h} 1$ & $33.98 \mathrm{dg}$ & $31.59 \mathrm{fg}$ & $35.86 \mathrm{k}$ & $198 \mathrm{ab}$ & $198 \mathrm{ac}$ & $198 \mathrm{ac}$ & $222 b$ & $187 \mathrm{a}$ \\
\hline $\mathbf{C}+\mathbf{H}$ & $40.67 \mathrm{~cd}$ & $38.40 \mathrm{cf}$ & $38.63 \mathrm{bf}$ & $39.22 b c$ & $53.66 \mathrm{~b}$ & 156be & 166eh & $170 \mathrm{bf}$ & 169eh & $111 \mathrm{~g}_{1}$ \\
\hline D+H & $39.36 \mathrm{cf}$ & $37.46 \mathrm{cg}$ & $39.51 \mathrm{bd}$ & $41.64 b$ & $53.42 b c$ & $162 \mathrm{ae}$ & 171eh & $169 \mathrm{bf}$ & $160 \mathrm{fh}$ & $112 \mathrm{~g}_{1}$ \\
\hline $\mathbf{Y}+\mathbf{C}+\mathbf{H}$ & $36.60 \mathrm{cf}$ & $38.04 \mathrm{cf}$ & $38.53 \mathrm{bf}$ & $38.62 \mathrm{bc}$ & $46.80 \mathrm{dg}$ & $178 \mathrm{ad}$ & 166eh & $168 \mathrm{cf}$ & 170eh & $131 \mathrm{dg}$ \\
\hline $\mathbf{A}+\mathbf{C}+\mathbf{H}$ & $37.58 \mathrm{cf}$ & $36.63 \mathrm{dh}$ & $40.92 b c$ & $32.90 \mathrm{df}$ & $44.09 \mathrm{fi}$ & $177 \mathrm{ad}$ & 176dg & $155 \mathrm{ef}$ & $210 \mathrm{bd}$ & $140 \mathrm{cf}$ \\
\hline$\ddot{\mathbf{U}}+\mathbf{C}+\mathbf{H}$ & $42.78 b c$ & $40.62 \mathrm{c}$ & $43.29 b$ & $38.05 b c$ & $50.22 \mathrm{be}$ & $144 \mathrm{cf}$ & $152 \mathrm{gh}$ & $142 \mathrm{f}$ & $175 \mathrm{dh}$ & $121 \mathrm{eg}$ \\
\hline $\mathbf{G}+\mathbf{C}+\mathbf{H}$ & $39.75 \mathrm{ce}$ & $36.27 \mathrm{dh}$ & $36.95 \mathrm{cf}$ & $35.51 \mathrm{cf}$ & $48.80 \mathrm{bf}$ & $161 \mathrm{ae}$ & $180 \mathrm{bf}$ & 180be & $194 \mathrm{bf}$ & $127 \mathrm{eg}$ \\
\hline $\mathbf{Y}+\mathrm{D}+\mathrm{H}$ & $36.72 \mathrm{cf}$ & 38.80ce & 39.16be & 36.20ce & 50.30be & $175 \mathrm{ae}$ & $162 \mathrm{eh}$ & $165 \mathrm{df}$ & $186 \mathrm{cf}$ & $120 \mathrm{fh}$ \\
\hline $\mathbf{A}+\mathbf{D}+\mathbf{H}$ & $38.46 \mathrm{cf}$ & $36.30 \mathrm{dh}$ & $36.53 \mathrm{cf}$ & $35.26 \mathrm{cf}$ & $48.36 \mathrm{cg}$ & $166 \mathrm{ae}$ & $179 b f$ & $181 \mathrm{be}$ & $193 b f$ & $126 \mathrm{eg}$ \\
\hline$\ddot{\mathbf{U}}+\mathbf{D}+\mathbf{H}$ & $42.69 b c$ & $39.27 \mathrm{~cd}$ & $42.96 \mathrm{~b}$ & $38.86 b c$ & 50.24be & $145 \mathrm{cf}$ & $160 \mathrm{fh}$ & $144 f$ & 172eh & $121 \mathrm{eg}$ \\
\hline $\mathbf{G}+\mathbf{D}+\mathbf{H}$ & $37.52 \mathrm{cf}$ & $36.10 \mathrm{dh}$ & $35.21 \mathrm{dg}$ & $37.55 b c$ & $51.83 \mathrm{bd}$ & $173 \mathrm{ae}$ & $179 \mathrm{bf}$ & $189 \mathrm{ad}$ & $181 \mathrm{cf}$ & $118 \mathrm{fh}$ \\
\hline
\end{tabular}

*Aynı sütunda, aynı harfle gösterilen ortalamalar arasında 0.01 seviyesinde farklılık yoktur. Y:Yonca, A:Ak üçgül, Ü:Çayır Üçgülü, G:Gazal boynuzu, Ç:Çok yıllık çim, D:Domuz ayrı̆̆ı ve H:Hindiba.

Çalışmada, iki yıl süresince biçimlerde elde edilen otun ADF oranları incelendiğinde, tüm biçimlerde yalın hindiba, yalın baklagil ve karışım parsellerinden elde edilen otun çok iyi sınıfta (ADF <31), yalın buğdaygillerin ise çok iyi ve iyi sınıfta olduğu söylenebilir [29]. Çalışma sonuçlarına bazı araştırıcıların sonuçlarıyla uyum içerisindedir [30,31]. Ortalama NDF oranı bakımından işlemler arasındaki farklılı̆̆ın istatistiksel olarak çok önemli olduğu belirlenmiştir (Tablo 4). 2017 yılının 1. biçiminde ortalama NDF oranı $\% 32.75(\mathrm{~A}+\mathrm{H})$ ile \%55.88 (yalın domuz ayrığı) arasında değişmiştir. İkinci biçimde ortalama NDF oranı \%31.73 (yalın ak üçgül) ile \%59.18 arasında belirlenmiştir. Çalışmanın 3. biçiminde en yüksek NDF oranı yalın domuz ayrığı (\%61.72), en düşük NDF oranı yalın ak üçgül (\%30.84) parselinden elde edilmiştir. 2018 yılında ise 1. 
biçimde ortalama NDF oranı değerleri \%27.45 ile \%46.41, İkinci biçimde ise \%35.86 ile \%63.01 arasında değişmiştir. Çalışmada kullanılan buğdaygillerin NDF kalite sınıfı çok iyi - kötü arasında belirlenmiştir [29]. Bu da bize buğdaygillerin çevre ve hasat zamanından çok hızlı etkilendiğini göstermektedir. Baklagiller ve hindibanın ise çok iyi kalitede olduğu söylenebilir. Çalışmada hindibada belirlenen NDF oranları bazı araştırıcıların belirlediği değerler ile benzerlik göstermektedir [24,25,26]. Her biçimde işlemlerde belirlenen ortalama NYD arasındaki farklılığın istatistiksel olarak çok önemli olduğu belirlenmiştir (Tablo 4).

2017 yılının 1. biçiminde elde edilen ortalama NYD 105 ile 207, ikinci biçimde 98 ile 209, üçüncü biçimde ise 94-220 arasında değişmiştir. Çalışmanın ikinci yılı birinci biçiminde en yüksek ortalama NYD yalın gazal boynuzunda (262), en düşük ise çok yıllık çimde (139) elde edilmiştir. İkinci biçiminin ortalama NYD birinci biçimine göre daha düşük olmuştur. Bu biçimde en yüksek ortalama NYD G+H karışımında, en düşük ise yalın domuz ayrığı parselinden elde edilmiştir. NYD standartlarına göre, hem 1. yıl hem de 2. yıl çalışmada belirlenen NYD değerlerinin birçoğu en iyi kalite, bir kısmı ise 1. ve 2. kalite sınıfında yer almıştır [32,33]. Genel olarak, buğdaygillerin NYD değeri daha düşüktür. Karışımlardan elde edilen otun NYD içeriği iklim faktörlerine, karşımda bulunan bitki türleri ve oranlarına, hasattaki olgunluk dönemine göre değişmektedir.

\section{SONUÇLAR}

Hindiba, bölgemizde yapay mera tesisi için üçgüller ve bazı buğdaygil yem bitkileri ile karışıma girebilir. Bölgede hindibanın yaş ve kuru ot veriminin, yaz dönemi hariç, oldukça iyi olduğu belirlenmiştir. Ayrıca, yaz aylarında sıcaklık stresinden etkilenmeyen çeşitlerle bölgemizde adaptasyon çalışmaları yapılmalıdır. Bu çalışmada, otlatma olgunluğu döneminde en yükssek toplam yeşil ve kuru ot verimi $\ddot{U}+\mathrm{D}+\mathrm{H}$ ve $\ddot{\mathrm{U}}+\mathrm{C}+\mathrm{H}$ karışımlarından elde edilmiştir. Ot verimi ve otun ham protein, ADF ve NDF içerikleri dikkate alındığında, bölgemiz ekolojisinde hindibanın çayır üçgülü ve domuz ayrığı ile çok iyi uyum sağladığı belirlenmiştir. Nitekim otlatma olgunluğu döneminde en iyi sonuçlar çayır üçgülü + hindiba ve çayır üçgülü + domuz ayrı̆̆ 1 + hindiba karışımlarından elde edilmiştir.

\section{TEŞEKKÜR}

Bu makale Mehmet CAN'ın Doktora tezinin bir bölümüdür. 2019 yılında OMÜ Fen Bilimleri Enstitüsü tarafından kabul edilmiştir.

\section{KAYNAKLAR}

[1] Acar, Z., Sabancı, C.O., Tan, M., Sancak, C., Kızılşimşek, M., Bilgili, U., Ayan, İ., Karagöz, A., Mut, H., Aşcı, Ö.Ö., Başaran, U., Kır, B., Temel, S., Yavuzer, G.B., Kırbaş, R. ve Pelen, M.A, 2015. Yem bitkileri üretiminde değişimler ve yeni arayışlar. Türkiye Ziraat Mühendisliği VIII. Teknik Kongresi. 508-547.

[2] Acar, Z, 2017. Kaba Yem Üretimi ve Sorunları. Türkiye'nin Hayvansal Üretimi (Mevcut Durum ve Gelecek) Sempozyumu. 10-11 Ocak Ankara. s:159-169.

[3] Gökkuş, A, 2014. Kurak alanlarda yapay mera kurulması ve yönetimi. Çanakkale Onsekiz Mart Üniversitesi Ziraat Fakültesi Dergisi, 2(2): 151-158.

[4] Altın, M., Tuna, C., Nizam, İ. ve Ateş, E, 2005. Pirinççi Köyü Meraları Dolgu Alanlarını Bitkilendirme Uygulamaları. VI. Tarla Bitkileri Kongresi, 5-9 Eylül, 1157-1162, Antalya.

[5] Bakır, Ö, 1985. Çayır ve Mera Islahı, Prensip ve Uygulamalar. Ankara Üniversitesi Ziraat Fakültesi Yayınları 947, Ders Kitabi: 272, 226 s, Ankara.

[6] Serin, Y. ve Tan, M, 2001. Yem Bitkileri Kültürüne Giriş. Atatürk Üniversitesi Ziraat Fakültesi Yayınları.

[7] Başaran, U., Akkbik, M., Mut, H., Gülümser, E., Çopur Doğrusöz, M., and Koçoğlu, S, 2018. HighPerformance liquid chromatography with refractive index detection for the determination of inulin in chicory roots. Analytical Letters, 51(1-2), 83-95 
[8] Straks, P.J., Samuel, W.C., and William, A.P, 2004. Determination of Forage Chemical Composition Using Remote Sensing. Journal of Range Management,57:635-640.

[9] Horrocks, R.D. and Vallentine, J.F, 1999. Harvested Forages. London, UK: Academic Press.

[10] Rumball, W.R.A., Skipp, R.G., Keogh, R. and Claydon, B, 2003. 'Puna II' forage chicory (Cichorium intybus L.). New Zealand Journal of Agricultural Research 46: 53-55.

[11] Özkan, U., Sevimay, C. S., ve Demirbağ, N.Ş, 2015. Yonca (Medicago sativa L.)'da Kış dormansisi ve ölçüm metodu. Türk Bilimsel Derlemeler Dergisi, (1), 51-53.

[12] Frame, J, 2008. Trifolium pratense L. http://www.fao.org/ag/AGP/AGPC/doc/gbase/DATA/Pf00349.HTM.

[13] Aş̧̧ı, Ö.Ö., Acar, Z., Basaran, U., Ayan, I. and Mut, H, 2010. Barley companion crop management in red clover establishment. African Journal of Agricultural Research, 5(1): 045-054.

[14] Sanderson, M. A., Labreveux, M., Hall, M. H. and Elwinger, G. F, 2003. Forage yield and persistence of chicory and English plantain. Crop Science, 43(3), 995-1000.

[15] Hume, D.E., Lyons, T.B. and Hay, R.J.M, 1995. Evaluation of Grasslands-Puna Chicory (Cichorium intybus L) in Various Grass Mixtures under Sheep Grazing. New Zealand Journal of Agricultural Research,317-328.

[16] Gülser, C., Aşkın, T. ve Özdemir, N, 2003. Ondokuz Mayıs Üniversitesi kampüs topraklarının erozyon duyarlılıklarının değerlendirmesi. OMÜ Zir. Fak. Dergisi, 18 (1):1-6.

[17] Moloney, S.C. and Milne, G.D, 1993. Establishment and management of Grasslands Puna chicory used as a specialist, high quality forage herb, Proceedings of the New Zealand Grassland, 55: 113-118.

[18] Aş̧̧ı, Ö.Ö, 2016. Karadeniz Bölgesi için Üçgül (Trifolium sp.) Cinsinin Önemi. Türk Tarım - Gıda Bilim ve Teknoloji Dergisi, 4(1): 1-4.

[19] Aşc1, Ö.Ö., ve Eğritaş, Ö, 2017. Yaygın Fiğ-Tahıl Karışımlarında Ot Verimi, Bazı Kalite Özellikleri ve Rekabetin Belirlenmesi. Tarım Bilimleri Dergisi - Journal of Agricultural Sciences 23:242-252.

[20] Aşc1, Ö.Ö., Acar, Z., and Arici, Y.K, 2015. Hay yield, quality traits and interspecies competition of forage pea-triticale mixtures harvested at different stages. Turkish Journal of Field Crops, 20(2), 166-173.

[21] Acar, Z., Gulumser, E., Asci, O. O., Basaran, U., Mut, H., and Ayan, I, 2017. Effects of sowing ratio and harvest periods on hay yields, quality and competitive characteristics of Hungarian vetch-cereal mixtures. Legume Research, 40(4), 677-683.

[22] Dhamala, N. R., Rasmussen, J., Carlsson, G., Søegaard, K. and Eriksen, J, 2017. N transfer in three-species grass-clover mixtures with chicory, ribwort plantain or caraway. Plant and soil, 413(1-2), 217-230.

[23] Clark, D. A., Anderson, C. B. and Berquist, T, 1990. Growth rates of 'Grasslands Puna' chicory (Cichorium intybus L.) at various cutting intervals and heights and rates of nitrogen. New Zealand journal of agricultural research 33: 213-217

[24] Li, G., Kemp, P. D. and Hodgson, J, 1997. Control of reproductive growth of Puna chicory by grazing management. Proceedings of the New Zealand Grassland Association 56: 213-217.

[25] Sanderson, M, 2010. Nutritive value and herbage accumulation rates of pastures sown to grass, legume and chicory mixtures. Agronomy Journal,102:728-733.

[26] Ditsch, C.D. and Sears, B, 2007. Chicory: An alternative livestock forage. (Lexington: University of Kentucky - College of Agriculture, Cooperative Extension Service: UoK Cooperative Extension Service). 
[27] Aşc1, Ö.Ö., ve Acar, Z, 2018. Kaba yemlerde kalite. TMMOB Ziraat Mühendisleri Odası yayııı ISBN-978605-01-1227-6

[28] Barry, T. N, 1998. The feeding value of chicory (Cichorium intybus) for ruminant livestock. The Journal of Agricultural Science 131,251-257.

[29] AFGC, 2015. Relative Feed Value. American Forage and Grassland Council.

[30] Skinner, R., Hall, M. and Sanderson, M, 2004. Water stress on Puna chicory and Lancelot Plantain. Morphological and physiological effects. Agricultural Research Service, USDA.

[31] Deak, A., Hall, M. H., Sanderson, M. A. and Archibald, D. D, 2007. Production and nutritive value of grazed simple and complex forage mixtures. Agronomy Journal, 99(3), 814-821.

[32] Lacefield, G. D, 1988. Alfalfa hay quality makes the difference. University of Kentucky Department of Agronomy. Agriculture and Natural Resources Publications, 32.

[33] Başaran, U., Gülümser, E., Doğrusöz, M. Ç., and Mut, H, 2018. Performance of Alfalfa under Different Intercropping Treatments. Yüzüncü Y1l Üniversitesi Tarım Bilimleri Dergisi, 28(3), 278-284. 